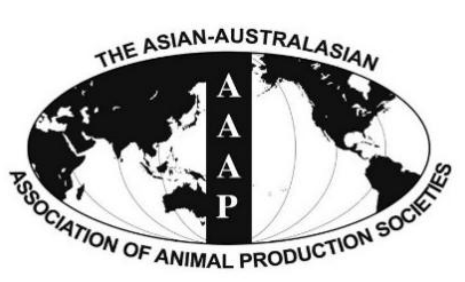

\title{
Effects of Nitrate Addition on Rumen Fermentation, Bacterial Biodiversity and Abundance
}

\author{
Liping Zhao, Qingxiang Meng, Liping Ren, Wei Liu ${ }^{1}$, Xinzhuang Zhang, \\ Yunlong Huo, and Zhenming Zhou* \\ State Key Laboratory of Animal Nutrition, College of Animal Science and Technology, \\ China Agricultural University, Beijing 100193, China
}

\begin{abstract}
This study examined changes of rumen fermentation, ruminal bacteria biodiversity and abundance caused by nitrate addition with Ion Torrent sequencing and real-time polymerase chain reaction. Three rumen-fistulated steers were fed diets supplemented with $0 \%, 1 \%$, and $2 \%$ nitrate (dry matter $\%$ ) in succession. Nitrate supplementation linearly increased total volatile fatty acids and acetate concentration obviously $(\mathrm{p}=0.02 ; \mathrm{p}=0.02 ; \mathrm{p}<0.01)$, butyrate and isovalerate concentration numerically $(\mathrm{p}=0.07)$. The alpha ( $>0.05)$ and beta biodiversityof ruminal bacteria were not affected by nitrate. Nitrate increased typical efficient cellulolytic bacteria species (Ruminococcus flavefaciens, Ruminococcus ablus, and Fibrobacter succinogenes) $(\mathrm{p}<0.01 ; \mathrm{p}=0.06 ; \mathrm{p}=0.02$ ). Ruminobactr, Sphaerochaeta, CF231, and BF311 genus were increased by $1 \%$ nitrate. Campylobacter fetus, Selenomonas ruminantium, and Mannheimia succiniciproducens were core nitrate reducing bacteria in steers and their abundance increased linearly along with nitrate addition level $(\mathrm{p}<0.01 ; \mathrm{p}=0.02 ; \mathrm{p}=0.04)$. Potential nitrate reducers in the rumen, Campylobacter genus and Cyanobacteria phyla were significantly increased by nitrate $(p<0.01 ; p=0.01)$. To the best of our knowledge, this was the first detailed view of changes in ruminal microbiota by nitrate. This finding would provide useful information on nitrate utilization and nitrate reducer exploration in the rumen.(Key Words: Nitrate, Rumen Fermentation, Bacterial Community, Ion Torrent Sequencing, Quantitative Polymerase Chain Reaction)
\end{abstract}

\section{INTRODUCTION}

Nitrate is an effective methane inhibitor (Zhou et al., 2011; Hulshof et al., 2012) and also a potential nitrogen source of non-protein nitrogen for ruminants. Nitrate, in the rumen, is reduced into ammonia via nitrite by nitrate reducing bacteria, i.e. Selenomonas ruminantium, Veillonella parvula, Wolinella succinogenes, Campylobacter fetus, and Mannheimia succiniciproducens (Lewis, 1951; Lin et al., 2013). Therefore, too much nitrate addition may result in nitrite accumulation in nitrate-unadapted ruminants, thereby contributing to nitrite poisoning. To avoid nitrite toxicity, nitrate addition level is suggested to be below 2.6\%

\footnotetext{
* Corresponding Author: Zhenming Zhou. Tel: +86-6231268, Fax: +86-62731268, E-mail: zhouzm@ @ cau.edu.cn

${ }^{1}$ Beijing Computing Center, Beijing 100094, China.

Submitted Jan. 31, 2015; Revised Mar. 6, 2015; Accepted Mar. 25, 2015
}

(Van Zijderveld et al., 2010). However, nitrite poisoning can be prevented either by following a nitrate adaptation period or by nitrate supplementation with sulfate (Van Zijderveld et al., 2010) and Escherichia coli (Sar et al., 2005). With a low addition level and a nitrate adaptation period, nitrate could be used as nitrogen source in ruminant feeding system.

Ruminal microbes are critically responsible for ruminant feed digestion, especially fibrous feed. Guo et al. (2009) found that nitrate changed rumen bacterial flora in the adapted and unadapted ruminants. Then, Lin et al. (2013) using Automated Ribosomal Intergenic Spacer Analysis (ARISA) reported that changes with nitrate in rumen fluid associated bacteria composition were more effective than that in the solid phase. But with the limitation of ARISA, how rumen bacteria are affected by nitrate is still unknown. Fiberous feed is a major ingredient in the ruminant diet as 
an energy supplier. Ruminococcus albus, Ruminococcus flavefaciens, and Fibrobacter succinogenes are dominant cellulolytic bacteria existing in the rumen. It is reported that F. succinogenes is inhibited by nitrate in the nitrateunadapted rumen in vitro culture (Hulshof et al., 2012; Zhou et al., 2012). However, the in vitro culture device can not exactly reflect rumen environment and may result in feed fermentation and bacterial population composition being different from the rumen (Slyter and Putnam, 1967). How does nitrate influence ruminal cellulolytic and nitratereducing bacteria in the nitrate-adapted rumen is still unknown. Next-generation DNA sequencing (NGS) of 16S rRNA has been used as a powerful tool to study gut microbiota (Zened et al., 2013). The NGS provides information on taxonomic diversity and abundance by analyzing 16s rRNA gene. Ion Torrent sequencing, as an NGS approach, is widely used to study bacterial biodiversity. The objectives of this study were to assess the effects of nitrate supplementation on ruminal fermentation, bacterial community composition and biodiversity of nitrate-adapted steers to provide useful information for long-term application of nitrate in ruminants.

\section{MATERIALS AND METHODS}

Animals in this study were handled in strict accordance with the Regulations for Laboratory Animals of Beijing. The protocol was approved by the Animal Welfare Committee of China Agricultural University (Permit No. DK1121).

\section{Animal trials and sampling}

Three rumen-fistulated Limousin $\times$ Jinan crossbred steers $(450 \pm 20 \mathrm{~kg})$ were used in the experiment. The animals were fed twice a day at approximately 08:00 am and 17:00 pm and had ad libitum access to water. The experimental diet consisted of corn straw and concentrate mixture (70:30, $\mathrm{w} / \mathrm{w})$ to meet metabolizable energy requirements $(1.3 \mathrm{x}$ maintenance). The concentrate mixture consisted of $30 \%$ corn, $18 \%$ cotton seed meal, $10 \%$ rapeseed meal, $12 \%$ wheat bran, $23 \%$ distillers dried grains with soluble, $1.2 \%$ stone powder, $1.2 \%$ salt, $2 \%$ sodium bicarbonate, $1 \%$ calcium hydrogen phosphate, $0.5 \%$ magnesium oxide, and $0.6 \%$ premix on a dry matter basis.

The animals received three experimental diets in succession, which differed in the nitrate supplementation level: $0 \%$ nitrate $(0 \mathrm{NR}), 1 \%$ nitrate $(1 \mathrm{NR})$, and $2 \%$ nitrate (2NR). Urea was used in $0 \mathrm{NR}$ and $1 \mathrm{NR}$ to balance crude protein concentration. Two-week adaptation was necessary for urea and nitrate treatment before sampling. Nitrate was added into the rumen in an increasing order of concentration to prevent nitrate toxicity, 2-day $0.5 \%$ and 12 day $1 \%$ nitrate diet for $1 \mathrm{NR}$, and 2-day $1.5 \%$ and 12 -day nitrate diet for $2 \mathrm{NR}$. Ruminal fluid was collected $6 \mathrm{~h}$ postfeeding, and stored at $-80^{\circ} \mathrm{C}$ for real-time polymerase chain reaction (PCR) and Ion Torrent sequencing. Another sample of ruminal fluid $(10 \mathrm{~mL})$ was stored at $-20^{\circ} \mathrm{C}$ for the assessment of fermentation parameters (ammonia nitrogen and volatile fatty acids).

\section{Chemical analyses}

Ruminal fluid $\mathrm{pH}$ was measured with a portable $\mathrm{pH}$ meter coupled to a glass electrode (Model PHS-3C, Shanghai Leici Scientific Instrument Co., Ltd., Shanghai, China). Volatile fatty acids (VFAs) were analyzed with a gas chromatograph Agilent 6890 (Agilent Technologies Inc., Santa Clara, CA, USA) equipped with an HP-INNO wax capillary column $(30 \mathrm{~m} \times 0.32 \mathrm{~mm})$ (Erwin et al., 1961). Ammonia nitrogen $\left(\mathrm{NH}_{3}-\mathrm{N}\right)$ was determined by the method reported by Broderick and Kang (1980).

\section{DNA extraction}

Total genomic DNA was extracted from $200 \mu \mathrm{L}$ ruminal fluid using a fecal DNA extraction toolkit (Tiangen Biotech Co., Beijing, China) combining a bead-beat with an oscillator (Precellys 24,Bertin Technology, Montigny-leBretonneux, France). Rotating speed of the oscillator was $5,500 \mathrm{rpm}$ with two circulations and $30 \mathrm{~s}$ per circulation.

\section{S primers and amplicon library generation}

The PCR amplification of the 16S rRNA V3 region was performed with the primers F357 and R534 (F357: 5'CCTACGGGAGGCAGCAG-3'; R534: 5'-ATTACCGCGG CTGCTGG-3'). The 5'-end of the reverse primers were fused to an Ion A adaptor plus key sequence and a sample barcode sequence, whereas the forward primers were fused to a truncated Ion P1 adapter sequence. The primers were diluted and pooled. For amplicon library preparation, $4 \mathrm{ng}$ of each genomic DNA, 1 U Platinum Taq DNA polymerase High Fidelity, $5 \mathrm{mM}$ dNTPs, $2 \mathrm{mM} \mathrm{MgCl}_{2}$ (all from Life Technologies, Gaithersburg, MD, USA), and 10 pmol primer-mix were used per $25 \mu \mathrm{L}$ amplification reaction. The PCR conditions consisted of $3 \mathrm{~min}$ at $94^{\circ} \mathrm{C}$, followed by 35 cycles of $15 \mathrm{~s}$ at $94^{\circ} \mathrm{C}, 15 \mathrm{~s}$ at $58^{\circ} \mathrm{C}, 10 \mathrm{~s}$ at $68^{\circ} \mathrm{C}$, and a final elongation step of $30 \mathrm{~s}$ at $68^{\circ} \mathrm{C}$. The amplicon of $16 \mathrm{~S}$ rRNA V3 was purified using QIAquick PCR Purification Kit (Cat. No. 28104). Quality control of the amplicon library was performed with BioRad Experion. DNA amount in the amplicon library was estimated using the Qubitds DNA HS assay on a Qubit 2.0 instrument (Life Technologies, USA).

\section{Emulsion polymerase chain reaction and sequencing}

Emulsion PCR was performed using the Ion OneTouch 200 Template Kit v2 DL (catalog No. MAN0006957; Life Technologies, USA). Sequencing of the amplicon libraries 
was performed on a 314 chip with the Ion Torrent personal genome machine system using the Ion Sequencing $200 \mathrm{kit}$ v2 (catalog No. MAN0007273; Life Technologies, USA).

\section{Quantification of selected bacteria species}

Total bacteria, nitrate-reducing bacteria and cellulolytic bacteria species were quantified using SYBR Green PCR RealMaster Mix (Tiangen Biotech, co., LTD, China) on an ABI 7300 Prism real-time PCR instrument (ABI, Foster City, CA, USA). They were quantified using the following PCR program, one cycle at $95^{\circ} \mathrm{C}$ for $15 \mathrm{~min}$ (initial denaturation), 40 cycles at $95^{\circ} \mathrm{C}$ for $15 \mathrm{~s}$ (denaturation) and $60^{\circ} \mathrm{C}$ for $32 \mathrm{~s}$ (annealing). All real-time PCR assays were performed triplicate. And primers sets are shown in Supplementary Table S1.

\section{Data analyses}

The Ion Torrent sequencing data was analyzed using the QIIME pipeline (Group Jumpstart Consortium Human Microbiome Project Data Generation Working Group, 2012). Filters were applied to sequences prior to phylogenetic analysis. Depending upon appropriate fragment size for V3 PCR (150 to $200 \mathrm{bp}$ ), bases after position 200 were trimmed and reads shorter than $150 \mathrm{bp}$ were removed. Then reads that more than $30 \%$ of bases $<$ Q20 were removed with NGS QC Toolkit (Patel and Jain, 2012). The left reads were removed with QIIME (Caporaso et al., 2010): i) homopolymers $>6 \mathrm{bp}$, and ii) reads with mismatched primers. After being filtered and trimmed, 216,443 reads remained with a length of $150 \mathrm{bp}$ to $200 \mathrm{bp}$ and with an average of 24,049 per sample (Supplementary Table S2). To calculate downstream diversity determination (alpha and beta diversity), all samples were subsampled to equal size 9,500 before subsequently comparing the bacterial communities. 16S rRNA operational taxonomic units (OTUs) were defined at the 0.97 similarity threshold. A total of 10,388 OTUs were calculated for all samples and the average OTUs for each treatment were 5,796 for 0NR; 5,641 for $1 \mathrm{NR}$; and 5,836 for 2NR. Based on the OTUs, rarefaction curve and alpha diversity indexes (i.e., abundance-based coverage estimation (ACE), Chao1, Shannon, and Simpson) were developed. Aligned sequences were also used to generate a phylogenetic tree with FastTree (Price et al., 2009) for beta diversity (weighted UniFrac) metrics. Clustering was visualized using principal coordinates analyses (PCoA, Supplementary Figure S2) for the weighted UniFrac distances. The rarefaction curve (Supplementary Figure S1) indicated that a reasonable number of individual samples had been taken. The sequence of each OTU was assigned to the lowest possible taxonomic rank with QIIME; a reference dataset from the Greengene database was used. The two-dimensional hierarchical clustering heatmap was drawn based on the number of reads of each OTU using $\mathrm{R}$ software; OTUs containing reads $<200$ were filtered.

Ruminal fermentation parameters $\left(\mathrm{pH}, \mathrm{NH}_{3}-\mathrm{N}\right.$, and VFA), total bacteria, nitrate-reducing and cellulolytic bacteria, bacterial community composition and diversity indexes were analyzed with the general linear model of SAS 9.0 (SAS Institute, Cary, NC, USA). Differences among treatments were assessed with Duncan's new multiple range test. Statistical significance was set to $\mathrm{p}<0.05$ and a tendency of difference was declared at $\mathrm{p}<0.1$.

\section{Nucleotide sequence accession number}

The sequencing data for the 16S rRNA genes are publicly available in the NCBI Short Read Archive under accession NO. PRJNA266283.

\section{RESULTS}

\section{Changes in ruminal fermentation parameters}

Table 1 shows the effects of nitrate supplementation on ruminal fermentation parameters $\left(\mathrm{pH}, \mathrm{NH}_{3}-\mathrm{N}\right.$, and VFAs).

Table 1. Effects of nitrate on ruminal fermentation parameters in nitrate- adapted steers

\begin{tabular}{|c|c|c|c|c|c|c|c|}
\hline & \multicolumn{3}{|c|}{ Treatments } & \multirow{2}{*}{ SEM } & \multirow{2}{*}{$\mathrm{p}$-value } & \multicolumn{2}{|c|}{ Contrast $^{1}$} \\
\hline & ONR & $1 \mathrm{NR}$ & $2 \mathrm{NR}$ & & & $P_{L}$ & $P_{Q}$ \\
\hline pH value & 7.65 & 7.71 & 7.73 & 0.10 & 0.37 & 0.38 & 0.22 \\
\hline $\mathrm{NH}_{3}-\mathrm{N}(\mathrm{mg} / \mathrm{dL})$ & 9.34 & 11.23 & 10.33 & 1.11 & 0.51 & 0.98 & 0.14 \\
\hline TVFAs (mmol/L) & $40.75^{b}$ & $46.73^{\mathrm{a}}$ & $51.05^{\mathrm{a}}$ & 2.00 & 0.02 & 0.01 & 0.77 \\
\hline Acetate $(\mathrm{mmol} / \mathrm{L})$ & $29.58^{b}$ & $33.51^{\mathrm{ab}}$ & $37.50^{\mathrm{a}}$ & 1.50 & 0.02 & 0.01 & 0.99 \\
\hline Propionate (mmol/L) & 8.03 & 8.96 & 9.52 & 0.47 & 0.15 & 0.06 & 0.78 \\
\hline Butyrate (mmol/L) & $2.54^{\mathrm{b}}$ & $3.48^{\mathrm{a}}$ & $3.30^{\mathrm{a}}$ & 0.14 & $<0.01$ & 0.01 & 0.01 \\
\hline Isobutyrate (mmol/L) & 0.13 & 0.14 & 0.21 & 0.04 & 0.40 & 0.21 & 0.61 \\
\hline Valerate (mmol/L) & 0.08 & 0.11 & 0.08 & 0.01 & 0.31 & 1.00 & 0.13 \\
\hline Isovalerate (mmol/L) & 0.40 & 0.53 & 0.45 & 0.03 & 0.07 & 0.37 & 0.04 \\
\hline Acetate:propionate & 3.68 & 3.74 & 3.94 & 0.17 & 0.59 & 0.34 & 0.75 \\
\hline
\end{tabular}

ONR, control; $1 \mathrm{NR}, 1 \%$ nitrate; $2 \mathrm{NR}, 2 \%$ nitrate; SEM, standard error of the mean; TVFAs: total volatile fatty acids

${ }^{1} P_{L}$ is liner tendency; $P_{Q}$ is quadratic tendency.

Different superscripts in the same row represent significant differences $(\mathrm{p}<0.05)$. 
Nitrate addition did not affect ruminal $\mathrm{pH}$ and $\mathrm{NH}_{3}-\mathrm{N}$ ( $\mathrm{p}=$ $0.37 ; \mathrm{p}=0.51$ ), but promoted ruminal fermentation. Total VFAs and acetate concentration increased linearly along with nitrate addition level in nitrate-adapted ruminants $\left(P_{L}=\right.$ $\left.0.01, P_{L}=0.01\right)$. Isovalerate and butyrate concentration showed a quadratic increasing tendency from $0 \mathrm{NR}$ to $2 \mathrm{NR}$ $\left(P_{Q}=0.04 ; P_{Q}=0.01\right)$. Even though ruminal fermentation was stimulated by nitrate, fermentation style was not changed because acetate/propionate ratio was not significantly affected by nitrate $(\mathrm{p}=0.59)$.

\section{Sequencing data analyses}

General information: Bacterial biodiversity was assessed with next-generation sequencing technology. The coverage of this study was $80.74 \%$ to $82.76 \%$ (not shown) meaning that most of the bacterial $16 \mathrm{~S}$ rRNA sequences were present in the samples. The alpha diversity was high for the higher alpha richness indexes (ACE, 6,403; Chao1, 5,934) and diversity indexes (Simpson, 0.996; Shannon, 9.98).

In accordance with the higher alpha diversity, a total of 18 bacterial phyla were discovered. Bacteroidetes and Firmicutes were two prevalent phyla in the rumen accounting for $55.84 \%$ and $32.39 \%$ of total sequence (Figure 1). Proteobacteria, Tenericutes, and Fibrobacter, minor phyla in the rumen, only accounted for $4.95 \%, 0.94 \%$, and $0.87 \%$ of total sequence, respectively. Chloroflexi, GN02 and TM6were not consistently present in all samples. Approximately, $2.61 \%$ of the total sequence belonged to unclassified bacterial phyla.

On the genus level, a total of 229 genera were

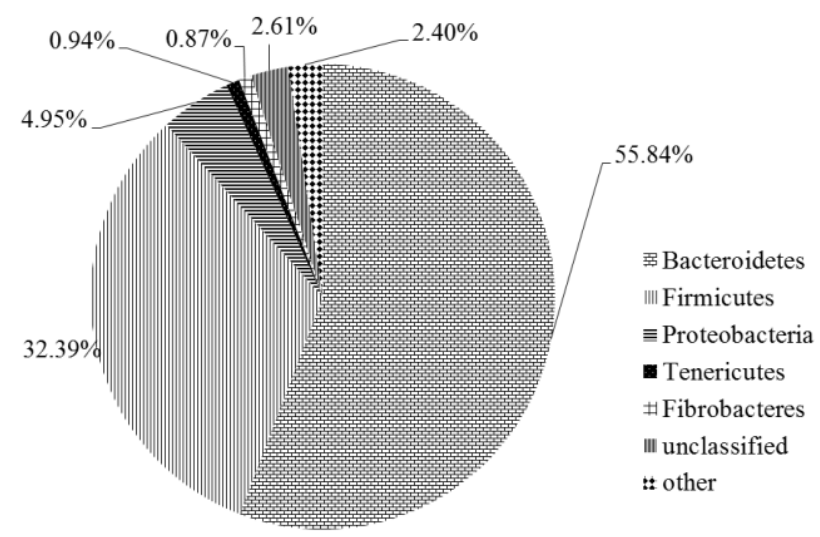

Figure 1. Average relative abundance of bacterial phyla in the rumen of steers fed different nitrate levels.

discovered. However, most of them were unclassified. Classified genera with high abundance (more than $0.1 \%$ ) mainly came from three phyla: Bacteroidetes, Firmicutes, and Proteobacteria. Prevotella, BF311, and CF231, three genera of Bacteroidetes, were the top three classified genus in this study. Prevotella was the most dominant genus, accounting for $16.13 \%$. Classified genera of Firmicutes were all in low abundance. The largest genus of Firmicutes was Ruminococcus, only accounting for $1.64 \%$ of total sequence.

\section{Changes of ruminal microbiota by nitrate}

Based on systematic analyses of the ruminal bacteria community composition, nitrate numerically decreased Bacteroidetes and increased Proteobacteria. However, there was no statistical difference in these bacterial phyla among

Table 2. Effects of nitrate on the relative abundance of bacterial phyla (\% of total sequences) using NGS technology

\begin{tabular}{|c|c|c|c|c|c|c|c|}
\hline & \multicolumn{3}{|c|}{ Treatments } & \multirow{2}{*}{ SEM } & \multirow{2}{*}{$\mathrm{p}$-value } & \multicolumn{2}{|c|}{ Contrast $^{1}$} \\
\hline & 0NR & $1 \mathrm{NR}$ & $2 \mathrm{NR}$ & & & $P_{L}$ & $P_{Q}$ \\
\hline Bacteroidetes & 57.36 & 56.81 & 53.35 & 2.25 & 0.44 & 0.25 & 0.62 \\
\hline Firmicutes & 33.12 & 29.82 & 34.24 & 2.97 & 0.58 & 0.80 & 0.33 \\
\hline Proteobacteria & 3.30 & 5.20 & 6.34 & 1.01 & 0.18 & 0.08 & 0.77 \\
\hline Unclassified & $2.43^{\mathrm{b}}$ & $3.11^{\mathrm{a}}$ & $2.28^{\mathrm{b}}$ & 0.13 & 0.01 & 0.45 & $<0.01$ \\
\hline Tenericutes & $0.81^{\mathrm{b}}$ & $1.32^{\mathrm{a}}$ & $0.70^{\mathrm{b}}$ & 0.12 & 0.03 & 0.56 & 0.01 \\
\hline Fibrobacteres & 0.71 & 1.06 & 0.83 & 0.20 & 0.49 & 0.70 & 0.27 \\
\hline TM7 & 0.43 & 0.64 & 0.56 & 0.07 & 0.22 & 0.25 & 0.18 \\
\hline Spirochaetes & $0.36^{\mathrm{b}}$ & $0.69^{\mathrm{a}}$ & $0.43^{\mathrm{b}}$ & 0.07 & 0.03 & 0.48 & 0.01 \\
\hline SR1 & 0.44 & 0.45 & 0.53 & 0.18 & 0.93 & 0.74 & 0.87 \\
\hline Verrucomicrobia & $0.35^{\mathrm{a}}$ & $0.20^{\mathrm{b}}$ & $0.14^{\mathrm{b}}$ & 0.04 & 0.02 & 0.01 & 0.39 \\
\hline Synergistetes & 0.14 & 0.15 & 0.20 & 0.03 & 0.43 & 0.24 & 0.63 \\
\hline Cyanobacteria & $0.18^{\mathrm{b}}$ & $0.22^{\mathrm{a}}$ & $0.09^{\mathrm{b}}$ & 0.02 & 0.01 & 0.02 & 0.01 \\
\hline Actinobacteria & 0.16 & 0.09 & 0.18 & 0.02 & 0.08 & 0.57 & 0.03 \\
\hline Elusimicrobia & 0.12 & 0.07 & 0.05 & 0.02 & 0.09 & 0.04 & 0.60 \\
\hline Lentisphaerae & 0.06 & 0.12 & 0.05 & 0.02 & 0.09 & 0.68 & 0.04 \\
\hline WPS & 0.02 & 0.02 & 0.02 & $<0.01$ & 0.33 & 0.21 & 0.45 \\
\hline
\end{tabular}

NGS, next-generation DNA sequencing; 0NR, control; 1NR, $1 \%$ nitrate; 2NR, $2 \%$ nitrate; SEM, standard error of the mean.

${ }^{1} P_{L}$ is liner tendency; $P_{Q}$ is quadratic tendency.

Different superscripts in the same row represent significant differences $(\mathrm{p}<0.05)$. 
Table 3. Effects of nitrate on common classified bacteria genera in ruminal fluid ranked by average relative abundance (\% of total sequences) using NGS technology

\begin{tabular}{|c|c|c|c|c|c|c|c|c|}
\hline \multirow{2}{*}{ Phyla } & \multirow{2}{*}{$\begin{array}{c}\text { Taxon } \\
\text { Genus }\end{array}$} & \multicolumn{3}{|c|}{ Treatments } & \multirow{2}{*}{ SEM } & \multirow{2}{*}{$\mathrm{p}$-value } & \multicolumn{2}{|c|}{ Contrast } \\
\hline & & 0NR & $1 \mathrm{NR}$ & $2 \mathrm{NR}$ & & & $P_{L}$ & $P_{Q}$ \\
\hline Bacteroidetes & Prevotella & 15.56 & 17.04 & 15.80 & 2.09 & 0.87 & 0.94 & 0.62 \\
\hline Bacteroidetes & BF311 & 2.60 & 4.74 & 2.86 & 0.53 & 0.06 & 0.74 & 0.02 \\
\hline Bacteroidetes & $C F 231$ & 2.17 & 2.61 & 2.24 & 0.12 & 0.08 & 0.71 & 0.03 \\
\hline Bacteroidetes & $Y R C 22$ & $1.77^{\mathrm{a}}$ & $0.70^{\mathrm{b}}$ & $0.89^{\mathrm{b}}$ & 0.23 & 0.03 & 0.03 & 0.07 \\
\hline Bacteroidetes & Paludibacter & 0.16 & 0.11 & 0.06 & 0.04 & 0.34 & 0.16 & 0.88 \\
\hline Fibrobacteres & Fibrobacter & 0.71 & 1.06 & 0.83 & 0.20 & 0.49 & 0.70 & 0.27 \\
\hline Firmicutes & Ruminococcus & 2.28 & 1.44 & 1.18 & 0.37 & 0.17 & 0.08 & 0.54 \\
\hline Firmicutes & Succiniclasticum & 1.41 & 1.10 & 1.59 & 0.23 & 0.38 & 0.60 & 0.21 \\
\hline Firmicutes & Clostridium & 1.03 & 1.10 & 1.26 & 0.15 & 0.57 & 0.32 & 0.82 \\
\hline Firmicutes & Butyrivibrio & 0.75 & 0.93 & 0.80 & 0.05 & 0.13 & 0.56 & 0.06 \\
\hline Firmicutes & Coprococcus & 0.41 & 0.36 & 0.54 & 0.08 & 0.36 & 0.32 & 0.30 \\
\hline Firmicutes & RFN20 & 0.28 & 0.42 & 0.42 & 0.07 & 0.32 & 0.21 & 0.41 \\
\hline Firmicutes & Oscillospira & 0.31 & 0.31 & 0.45 & 0.07 & 0.37 & 0.23 & 0.47 \\
\hline Proteobacteria & Campylobacter & $0.04^{\mathrm{b}}$ & $0.48^{\mathrm{b}}$ & $3.49^{\mathrm{a}}$ & 0.43 & $<0.01$ & $<0.01$ & 0.05 \\
\hline Proteobacteria & Ruminobacter & $0.53^{\mathrm{ab}}$ & $0.95^{\mathrm{a}}$ & $0.15^{\mathrm{b}}$ & 0.15 & 0.03 & 0.12 & 0.02 \\
\hline Proteobacteria & Succinivibrio & 0.28 & 0.64 & 0.18 & 0.14 & 0.13 & 0.63 & 0.06 \\
\hline Proteobacteria & Acinetobacter & 0.16 & 0.07 & 0.30 & 0.08 & 0.18 & 0.25 & 0.13 \\
\hline Proteobacteria & Lampropedia & 0.04 & 0.04 & 0.32 & 0.11 & 0.18 & 0.11 & 0.32 \\
\hline Proteobacteria & Desulfovibrio & 0.10 & 0.12 & 0.15 & 0.03 & 0.45 & 0.23 & 0.93 \\
\hline Proteobacteria & Pseudomonas & 0.12 & 0.11 & 0.08 & 0.04 & 0.79 & 0.52 & 0.90 \\
\hline Spirochaetes & Sphaerochaeta & $0.15^{\mathrm{b}}$ & $0.40^{\mathrm{a}}$ & $0.08^{\mathrm{b}}$ & 0.05 & 0.01 & 0.36 & $<0.01$ \\
\hline Spirochaetes & Treponema & 0.14 & 0.15 & 0.23 & 0.04 & 0.32 & 0.17 & 0.55 \\
\hline
\end{tabular}

NGS, next-generation DNA sequencing; 0NR, control; 1NR, $1 \%$ nitrate; 2NR, $2 \%$ nitrate; SEM, standard error of the mean.

${ }^{1} P_{L}$ is liner tendency; $P_{Q}$ is quadratic tendency.

Different superscripts in the same row represent significant differences $(\mathrm{p}<0.05)$.

the three treatments ( $p>0.1$; Table 2). Nitrate significantly affected minor phyla. Cyanobacteria, Tenericutes and Spirochaetes abundance were significantly increased by $1 \mathrm{NR}(\mathrm{p}=0.01 ; \mathrm{p}=0.03 ; \mathrm{p}=0.03)$. Verrucomicrobia and Elusimicrobia abundance were linearly decreased from $0 \mathrm{NR}$ to $2 \mathrm{NR}\left(P_{L}=0.01 ; P_{L}=0.04\right)$.

To evaluate the effects of nitrate on ruminal bacteria community composition, the genera whose abundance was higher than $0.1 \%$ were selected. Despite that nitrate decreased Bacteroidetes abundance, $1 \%$ nitrate addition trended to increase major genera of Bacteroidetes, BF311 and $C F 231$ numerically $(\mathrm{p}=0.06 ; \mathrm{p}=0.08)$ and decreased YRC22 statistically $(\mathrm{p}=0.03)$. Main genera of Firmicutes were not affected by nitrate addition. Nitrate supplementation had positive effects on Campylobacter genus $(\mathrm{p}<0.01$; Table 3$)$. Quadric curve changes were observed in Sphaerochaeta and Ruminobacter genus $\left(P_{Q}=\right.$ $\left.0.02 ; P_{Q}<0.01\right)$.

Based on Ion Torrent sequencing analyses, nitrate did not significantly affect alpha or beta diversity of ruminal bacteria (Table 4 and Supplementary Figure S2). The alpha diversity indexes (ACE, Chao1, Shannon, and Simpson) of the ruminal bacterial populations were not significantly affected by nitrate supplementation ( $>0.1$; Table 4$)$. The comparisons among bacterial communities by PCoA (Supplementary Figure S2) based on weighted UniFrac distance revealed no difference among treatments, indicating that nitrate concentration did not affect the

Table 4. Changes in bacterial richness and biodiversity by nitrate

\begin{tabular}{|c|c|c|c|c|c|c|c|}
\hline & \multicolumn{3}{|c|}{ Treatments } & \multirow{2}{*}{ SEM } & \multirow{2}{*}{ p-value } & \multicolumn{2}{|c|}{ Contrast $^{1}$} \\
\hline & 0NR & $1 \mathrm{NR}$ & $2 \mathrm{NR}$ & & & $P_{L}$ & $P_{Q}$ \\
\hline$\overline{\mathrm{ACE}}$ & 6,275 & 6,701 & 6,228 & 403.34 & 0.68 & 0.94 & 0.40 \\
\hline Chaol & 5,862 & 6,320 & 5,740 & 400.87 & 0.59 & 0.84 & 0.33 \\
\hline Shannon & 0.996 & 0.997 & 0.996 & 0.13 & 0.97 & 0.97 & 0.81 \\
\hline Simpson & 9.97 & 10.01 & 9.98 & 0.001 & 0.77 & 0.79 & 0.52 \\
\hline
\end{tabular}

SEM, standard error of the mean; ACE: abundance-based coverage estimation; 0NR: control; 1 NR: $1 \%$ nitrate; 2 NR: $2 \%$ nitrate.

${ }^{1} P_{L}$ is liner tendency; $P_{Q}$ is quadratic tendency. 
ruminal bacterial population. The effect of nitrate on main bacteria groups can be observed by double hierarchal cluster analysis on abundant genera clustered by treatments (Supplementary Figure S3). All bacteria groups were classified into 5 clusters: unclassified Bacteroidales (OTU214424); Campylobacter and unassigned bacteria; unclassified Bacteroidales (OTU154248) and Ruminococcus; Prevotella, unclassified Bacteroidales (OTU301305 and OTU325179).

\section{Changes of selected bacteria abundance}

Table 5 showed the effects of nitrate on the abundance of total bacteria and selected bacterial species. The number of total bacteria was not obviously different among treatment $(\mathrm{p}=0.06)$. The main cellulolytic bacteria in the rumen, $R$. ablus, $R$. flavefaciens, and $F$. succinogenes, were promoted. The $R$. ablus and $F$. succinogenes abundance were linearly increased by nitrate $\left(P_{L}=0.02 ; P_{L}=0.01\right)$, and $R$. flavefaciens abundance was increased quadraticly $\left(P_{Q}<0.01\right)$.

Nitrate increased the $C$. fetus, $M$. succiniciproducens, and $S$. ruminantium abundance significantly $\left(P_{L}<0.01 ; P_{L}=\right.$ $\left.0.02 ; P_{Q}=0.01\right)$. The $W$. succinogenes and $V$. parvula abundance were not affected by nitrate addition $(\mathrm{p}=0.14 ; \mathrm{p}$ $=0.88$ ). C. fetus/Campylobacter ratio was significantly increased with the addition of nitrate (Figure 2), indicating that some other strain of Campylobacter obviously increased with nitrate supplementation and was a potential nitrate-reducing bacteria.

\section{DISCUSSION}

\section{Ruminal fermentation parameters}

Nitrate as a potential nitrogen source and methane inhibitor has been widely studied. Like urea, it is water soluble and metabolized to ammonia by ruminal bacteria in the rumen (Lewis, 1951). In this study, urea was selected to balance nitrogen content of treatments. The equal total

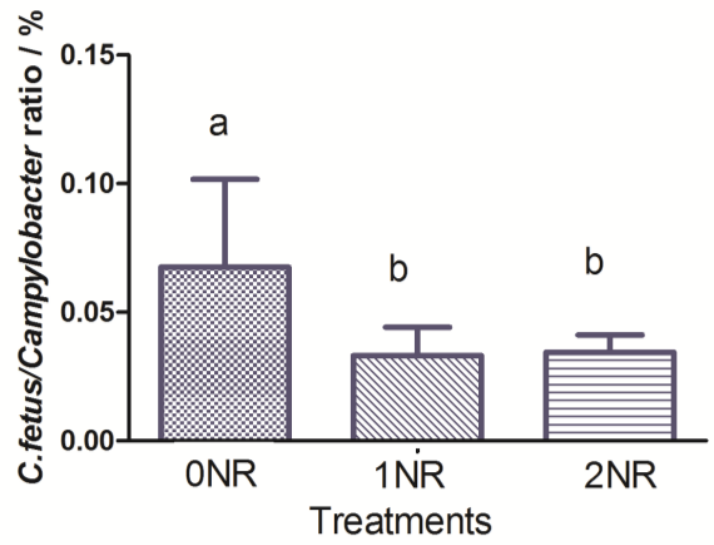

Figure 2. C. fetus to Campylobacter ratio of different treatments.

nitrogen and rapid degradable nitrogen content resulted in no difference in ruminal ammonia concentration between control and nitrate treatments. Besides, $\mathrm{NH}_{3}-\mathrm{N}$ concentration of ruminal fluid was from $9.34 \mathrm{mg} / \mathrm{dL}$ to $11.23 \mathrm{mg} / \mathrm{dL}$, which was adequate for bacteria metabolism and growth (Weakley et al., 1983). Nitrate would inhibit ruminal fermentation of a nitrate-unadapted animal (Guo et al., 2009), while this inhibition would disappear when the animal adapted to dietary nitrate (Zhou et al., 2012). This study confirmed the conclusion that nitrate addition linearly increased TVFAs and VFAs concentration (e.g. acetate) in nitrate - adapted animals. The VFAs were products of ruminal microbe fermentation, whereas the total bacteria abundance was not increased with the addition of nitrate. Therefore, the increase of TVFA concentration in nitrate treatments may result from increased activity of ruminal bacteria fermentation by nitrate addition. Acetate is produced in the rumen principally by microbiological activity on cellulose and hemicellulose (Ballard, 1972), hydrogen generation accompanying this procedure provides an electron for nitrate reduction in the rumen. The hydrogen transfer releases the inhibitory effect of hydrogen on fiber fermentation and increases the degradation of cellulose

Table 5. Influence of nitrate on total bacteria, cellulolytic and nitrate-reducing bacteria abundance using qPCR technology

\begin{tabular}{|c|c|c|c|c|c|c|c|}
\hline & \multicolumn{3}{|c|}{ Treatments } & \multirow{2}{*}{ SEM } & \multirow{2}{*}{ p-value } & \multicolumn{2}{|c|}{ Contrast $^{1}$} \\
\hline & ONR & $1 \mathrm{NR}$ & $2 \mathrm{NR}$ & & & $P_{L}$ & $P_{Q}$ \\
\hline Total Bacteria (log copies) & 11.36 & 11.18 & 11.21 & 0.05 & 0.06 & 0.06 & 0.13 \\
\hline R. flavefaciens (\%) & $0.3463^{\mathrm{b}}$ & $0.7889^{\mathrm{a}}$ & $0.6600^{\mathrm{a}}$ & 0.041 & $<0.01$ & $<0.01$ & $<0.01$ \\
\hline R. ablus (\%) & 0.0115 & 0.0185 & 0.0266 & 0.003 & 0.06 & 0.02 & 0.9 \\
\hline F. succinogenes (\%) & $0.0392^{\mathrm{b}}$ & $0.2240^{\mathrm{a}}$ & $0.2687^{\mathrm{a}}$ & 0.052 & 0.02 & 0.01 & 0.29 \\
\hline S. ruminantium (\%) & $0.2778^{\mathrm{b}}$ & $0.6176^{\mathrm{a}}$ & $0.4453^{\mathrm{ab}}$ & 0.080 & 0.02 & 0.30 & 0.01 \\
\hline C. fetus $(\%)$ & $0.00003^{b}$ & $0.0002^{\mathrm{b}}$ & $0.0015^{\mathrm{a}}$ & $<0.001$ & $<0.01$ & $<0.01$ & 0.05 \\
\hline M. succiniciproducens (\%) & $0.0006^{\mathrm{b}}$ & $0.0016^{\mathrm{b}}$ & $0.0068^{\mathrm{a}}$ & 0.002 & 0.04 & 0.02 & 0.29 \\
\hline W. succinogenes (\%) & 0.0031 & 0.0064 & 0.0041 & 0.001 & 0.14 & 0.21 & 0.13 \\
\hline V. parvula $(\%)$ & 0.0001 & 0.0001 & 0.0002 & $<0.001$ & 0.82 & 0.67 & 0.66 \\
\hline
\end{tabular}

qPCR, quantitative polymerase chain reaction; 0NR, control; $1 \mathrm{NR}, 1 \%$ nitrate; 2NR, $2 \%$ nitrate; SEM, standard error of the mean.

${ }^{1} P_{L}$ is liner tendency; $P_{Q}$ is quadratic tendency.

Different superscripts in the same row represent significant differences $(\mathrm{p}<0.05)$. 
(Van Zijderveld et al., 2010) and acetate production. In the present study, an increase in cellulolytic bacteria (Table 5) contributed to cellulose degradation and acetate production. This is consistent with the findings of Dai et al. (2009), where nitrate increased butyrate and isovalerate.

\section{Changes of ruminal bacteria community composition}

Deep assessment of rumen fluid samples with nextgeneration sequencing technology provided a more detailed view of ruminal bacteria than DDGE and ARISA. As we all know, ruminal bacteria are greatly affected by animal species, feed style etc. In this study, more bacteria phyla and higher ACE and Chaol indexes were detected because of the complex feed ingredients and animals species (Lee et al., 2012; Zened et al., 2013). The majority of sequences belonged to three core phyla in the rumen (Bacteroidetes, Firmicutes, and Protoeabacteria) (Thoetkiattikul et al., 2013). Prevotella is an important genus for non-plant fiber degradation. As the major classified genus, Prevotella only accounted for $16.13 \%$, which was much lower than results of Lee et al. (2012) for the lower concentrate diet.

Nitrate addition could change rumen bacterial community composition in steers (Lin et al., 2013) by the following three mechanisms: i) toxicity by nitrite, a nitratereduction pathway intermediate; ii) competition for hydrogen; iii) changes in Eh (Guo et al., 2009; Zhou et al., 2012). In this study we gave a detailed answer regarding nitrate affected microbiota. Thoetkiattikul et al. (2013) reported that Bacteroidetes was a major non-cellulosic plant constituent degrader in the rumen. Most Bacteroidetes stains are hemicellulolytic, proteolytic or amylolytic bacteria (Marais et al., 1988; Evans et al., 2011). Abundance of three top genera of Bacteroidetes (Prevotella, $B F 311$, and $C F 231$ ) was raised by $1 \%$ nitrate. Moreover, Ruminobacter, starch-degradation bacteria, was also increased by $1 \%$ nitrate. In summary low nitrate addition stimulated Prevotella, CF231, BF311 and Ruminobacter metabolism and growth, while $2 \%$ nitrate inhibited them.

Fiber is an important nutrient source for ruminants' growth and rumen health. In this experiment, we found that main fibrolytic bacteria groups were numerically increased, such as Fibrobacter, Clostridium, and Butyrivibrio. However, no statistical difference among treatments was found because of large difference among samples. On species level, nitrate addition promoted fibrolytic bacteria metabolism and growth. Three important ruminal cellulolytic bacteria species (R. ablus, R. flavefaciens, and $F$. succinogenes) were significantly increased. Isobutyrate, valerate, and isovalerate were main isoacids in the rumen. It was reported that isoacids were essential and required by fibrolytic bacteria (Andries et al., 1987). Concentration of ruminal isoacids increased in nitrate treatments resulting in higher fibrolytic bacteria abundance in nitrate treatment.

\section{Nitrate reducing bacteria in the rumen}

Nitrate reduction to ammonia is a critical step of nitrate metabolism in the rumen. It is reduced by nitrate reductase in assimilatory or dissimilatory way. Ruminal bacteria with nitrate reducing ability are $S$. ruminantium, C. fetus, $M$. succiniciproduces, $W$. succinogenes, and $V$. parvula (Stewart et al., 1997; Lin et al., 2011). In this study, nitrate increased the $C$. fetus, $M$. succiniciproducens, and $S$. ruminantium abundance significantly indicating that they were core nitrate-reducing bacteria in nitrate-adapted steers. However, the relative abundance of $S$. ruminantium was $0.4469 \%$, much lower than that reported by Lin et al. (2013) due to difference in feeding conditions, diet, and animal species. Were there other nitrate-reducing bacteria present in the rumen? In nature, most nitrate reducers are found in Proteobacteria, Actinobacteria, Firmicutes, and Cyanobacteria (Bru et al., 2007; Palmer et al., 2012). Based on deep analysis of sequencing data, we found that Proteobacteria and Cyanobacteria were linearly/quadratically increased with nitrate addition. On genus taxon, Campylobacter of Proteobacteria was linearly increased with nitrate supplementation. We proposed that there are undiscovered nitrate reducing bacteria in Proteobacteria (especially Campylobacter genus) and Cyanobacteria phyla.

Campylobacter is a genus of Gram-negative, microaerophilic, oxidase-positive, non-fermentative bacteria. Many species of Campylobacter contain the nitrate reductase gene, such as Campylobacter jejuni, Campylobacter lari, Campylobacter concisus, Campylobacter fetus, and Campylobacter coli etc (Parkhill et al., 2000; Miller et al., 2008). C. fetus was the only nitrate reducing bacteria from Campylobacter genus found in the rumen in the present study. Even though its abundance was increased with the addition of nitrate (Table 5 ), it accounted for less than $0.10 \%$ of Campylobacter genus. Moreover, C. fetus/Campylobacter ratio significantly increased (Figure 2) in nitrate treatments indicating that there were one or more strains of Campylobacter stains which obviously increased with nitrate supplementation. This confirmed our assumption above that some potential nitrate-reducing bacteria exist in Campylobacter. Further studies on nitrate reductase gene or cultivation approach need to be performed to verify this hypothesis.

Cyanobacteria are common ruminal bacterial phyla and play an important role in nitrate assimilation and reduction of methane production (Prasanna et al., 2002; Flores et al., 2005). In this experiment, the relative abundance of Cyanobacteria was significantly increased in 1NR indicating that the nitrate assimilatory reduction was promoted in low nitrate addition treatment.

In conclusion, the amount of total bacteria was not 
significantly changed by nitrate in nitrate-adapted steers, whereas the bacteria community composition was changed. Nitrate promoted growth of efficient ruminal cellulolytic bacteria species $(R$. ablus, $R$. flavefaciens, and $F$. succinogenes). Low nitrate addition level increased relative abundance of non-cellulose degraders. As to nitrate reducing bacteria, in addition to the three core nitrate reducing bacteria (C. fetus, M. succiniciproducens, and $S$. ruminantium), some other potential nitrate reducing bacteria may exist in Cyanobacteria phyla and Campylobacter genus.

Nitrate stimulated rumen fermentation in nitrate-adapted steers when the addition level was less than $2 \%$. So nitrate could be used in ruminant production as potential nitrogen source. However, the effects of nitrate addition on production performance and meat quality, the safety on ruminants and the optimal addition level should be carefully studied before its utilization in animal production.

\section{ACKNOWLEDGMENTS}

This work was supported by the National Natural Science Fund of China (No. 31101738), National Scientific Programme (2011CB302705), and China Agricultural Research System (CARS-38). We thank Xiaodong Li and Jinwei Zhao for their technical assistance. The authors also wish to acknowledge the students of Beef Cattle Research Center of CAU for their support on this experiment.

\section{REFERENCES}

Andries, J. I., F. X. Buysse, D. L. Debrabander, and B. G.Cottyn. 1987. Isoacids in ruminant nutrition: Their role in ruminal and intermediary metabolism and possible influences on performances - A review. Anim. Feed Sci. Technol. 18:169180.

Ballard, F. J. 1972. Supply and utilization of acetate in mammals. Am. J. Clin. Nutr. 25:773-779.

Broderick, G. A. and J. H. Kang. 1980. Automated simultaneous determination of ammonia and total amino acids in ruminal fluid and in vitro media. J. Dairy Sci. 63:64-75.

Bru, D., A. Sarr,and L. Philippot. 2007. Relative abundances of proteobacterial membrane-bound and periplasmic nitrate reductases in selected environments. Appl. Environ. Microbiol. 73:5971-5974.

Caporaso, J. G., J. Kuczynski, J. Stombaugh, K. Bittinger, F. D. Bushman, E. K. Costello, N. Fierer, A. G. Pena, J. K. Goodrich, and J. I. Gordon et al. 2010. QIIME allows analysis of highthroughput community sequencing data. Nat. Methods 7:335336.

Dai, J. F., Q. X. Meng, and Z. M. Zhou. 2009. Effect of nitrate addition level on in vitro ruminal fermentation characteristics and microbial efficiency. Scientia AgricSinica. 43:3418-3424.

Denman, S. E. and C. S. McSweeney. 2006. Development of a real-time PCR assay for monitoring anaerobic fungal and cellulolytic bacterial populations within the rumen. FEMS
Microbiol. Ecol. 58:572-582.

Erwin, E. S., G. J. Marco, and E. M. Emery. 1961. Volatile fatty acid analyses of blood and rumen fluid by gas chromatography. J Dairy Sci. 44:1768-1771.

Evans, N. J., J. M. Brown, R. D. Murray, B. Getty, R. J. Birtles, C. A. Hart, and S. D. Carter. 2011. Characterization of novel bovine gastrointestinal tract Treponema isolates and comparison with bovine digital dermatitis treponemes. Appl. Environ. Microbiol. 77:138-177.

Flores, E., J. E. Frías, L. M. Rubio, and A. Herrero. 2005. Photosynthetic nitrate assimilation in cyanobacteria. Photosyn. Res. 83:117-133.

Group Jumpstart Consortium Human Microbiome Project Data Generation Working Group. 2012. Evaluation of 16S rDNAbased community profiling for human microbiome research. PLoS ONE. 7(6):e39315.

Guo, W. S., D. M. Schaefer, X. X. Guo, L. P. Ren, and Q. X.Meng. 2009. Use of nitrate-nitrogen as a sole dietary nitrogen source to inhibit ruminal methanogenesis and to improve microbial nitrogen synthesis in vitro. AsianAustralas. J. Anim. Sci. 22: 542-549.

Hulshof, R., A. Berndt, W. Gerrits, J. Dijkstra, S. M. van Zijderveld, J. R. Newbold, and H. B. Perdok. 2012. Dietary nitrate supplementation reduces methane emission in beef cattle fed sugarcane-based diets. J. Anim. Sci. 90:2317-2323.

Isaacson, R. and H. B. Kim. 2012. The intestinal microbiome of the pig. Anim. Health Res. Rev. 13:100-109.

Lee, H. J., J. Y. Jung, Y. K. Oh, S. Lee, E. L. Madsen, and C. O. Jeon. 2012. Comparative survey of rumen microbial communities and metabolites across one caprine and three bovine groups, using bar-coded pyrosequencing and $1 \mathrm{H}$ nuclear magnetic resonance spectroscopy. Appl. Environ. Microbiol. 78: 5983-5993.

Lewis, D. 1951. The metabolism of nitrate and nitrite in the sheep. 1. The reduction of nitrate in the rumen of the sheep. Biochem J. 48:175-180.

Lin, M., D. M. Schaefer, W. S. Guo, L. P. Ren, and Q. X. Meng. 2011. Comparisons of in vitro nitrate reduction, methanogenesis, and fermentation acid profile among rumen bacterial, protozoal and fungal fractions. Asian Australas. J. Anim. Sci. 24:471-478.

Lin, M., W. Guo, Q. Meng, D. M. Stevenson, P. J. Weimer, and D. M. Schaefer. 2013. Changes in rumen bacterial community composition in steers in response to dietary nitrate. Appl. Environ.Biotech. 97:8719-8727.

Marais, J. P., J. J. Therion, R. I. Mackie, A. Kistner, and C. Dennison. 1988. Effect of nitrate and its reduction products on the growth and activity of the rumen microbialpopulation. Br. J. Nutr. 59: 301-313.

Miller, W. G., G. Wang, T. T. Binnewies, and C. T. Parker. 2008. The complete genome sequence and analysis of the human pathogen Campylobacter lari. Foodborne Pathog. Dis. 5:371386.

Palmer, K. andM. A. Horn. 2012. Actinobacterial nitrate reducers and proteobacterial denitrifiers are abundant in $\mathrm{N}_{2} \mathrm{O}$ metabolizing palsa peat. Appl. Environ. Microbiol. 78:55845596.

Parkhill, J., B. W. Wren, K. Mungall,J. M. Ketley, C. Churcher, D. Basham, T. Chillingworth, R. M. Davies, T. Feltwell, and S. 
Holroyd et al. 2000. The genome sequence of the food-borne pathogen Campylobacter jejunireveals hypervariable sequences. Nature 403(6770):665-668.

Patel, R. K. and M. Jain. 2012. NGS QC Toolkit: A toolkit for quality control of next generation sequencing data. PLoS ONE, 7(2):e30619.

Pitta, D. W., W. E. Pinchak, S. E. Dowd, J. Osterstock, V. Gontcharova, E. Youn, K. Dorton, I. Yoon, B. R. Min, J. D. Fulford, T. A. Wickersham, and D. P. Malinowski. 2010. Rumen bacterial diversity dynamics associated with changing from bermudagrass hay to grazed winter wheat diets. Microb.Ecol. 59:511-522.

Price, M. N., P. S. Dehal, and A. P. Arkin. 2009. FastTree: computing large minimum evolution trees with profiles instead of a distance matrix. Mol. Biol. Evol. 26:1641-1650.

Prasanna, R., V. Kumar, S. Kumar, A. Kumar Yadav, U. Tripathi, A. Kumar Singh, M. C. Jain, P. Gupta, P. K. Singh, and N. Sethunathan. 2002. Methane production in rice soil is inhibited by cyanobacteria. Microbiol.Res. 157:1-6.

Sar, C., B. Mwenya, B. Santoso, K. Takaura, R. Morikawa, N. Isogai, Y. Asakura, Y. Toride, and J. Takahashi. 2005. Effect of Escherichia coli wild type or its derivative with high nitrite reductase activity on in vitro ruminal methanogenesis and nitrate/nitrite reduction. J. Anim. Sci. 83:644-652.

Slyter, L. L. and P. A. Putnam. 1967. In vivo vs in vitro continuous culture of ruminal microbial populations.J. Anim. Sci. 26: 1421-1427.

Stewart, C. S., H. J. Flint, and M. P. Bryant. 1997. The rumen bacteria. In:The Rumen Microbial Ecosystem, 2nd ed.,By (P. N. Hobson, and C. S. Stewart). Blackie Academic and Professional, London, UK. 10-72.
Stevenson, D. M. and P. J. Weimer. 2007. Dominance of Prevotella and low abundance of classical ruminal bacterial species in the bovine rumen revealed by relative quantification real-time PCR. Appl. Environ.Biotech.75:165-174

Thoetkiattikul, H., W. Mhuantong, T. Laothanachareon, S. Tangphatsornruang, V. Pattarajinda, L. Eurwilaichitr, and V. Champreda. 2013. Comparative analysis of microbial profiles in cow rumen fed with different dietary fiber by tagged $16 \mathrm{~S}$ rRNA gene pyrosequencing. Curr. Microbiol. 67:130-137.

Van Zijderveld, S. M., W. J. J. Gerrits, J. A. Apajalahti, J. R. Newbold, J. Dijkstra, R. A. Leng, and H. B. Perdok. 2010. Nitrate and sulfate: Effective alternative hydrogen sinks for mitigation of ruminal methane production in sheep. J. Dairy Sci. 93:5856-5866.

Weakley, D. G. and F. N. Owens. 1983. Influence of ammonia concentration on microbial protein synthesis in the rumen. Oklahoma Agr. Exp. Sta. MP-114, 39.

Zened, A., S. Combes, L. Cauquil, J. Mariette, C. Klopp, O. Bouchez, M. A. Troegeler, and F. Enjalbert. 2013. Microbial ecology of the rumen evaluated by 454 GS FLX pyrosequencing is affected by starch and oil supplementation of diets. FEMS Microbiol. Ecol. 83:504-514.

Zhou, Z., Q. Meng, and Z. Yu. 2011. Effects of methanogenic inhibitors on methane production and abundances of methanogens and cellulolytic bacteria in in vitro ruminal cultures. Appl. Environ. Microbiol. 77:2634-2639.

Zhou, Z., Z. Yu, andQ. Meng. 2012. Effects of nitrate on methane production, fermentation, and microbial populations in in vitro ruminal cultures. Bioresour. Technol.103:173-179. 